\title{
Self-Adaptive Fuzzy PI Control in Energy Distribution of Pure Electric Vehicle with Dual-Energy Storage System
}

\author{
Shuang $\mathrm{Du}^{1,2}$ and Chuncheng $\mathrm{Zuo}^{2 *}$ \\ ${ }^{1}$ College of Mechanical Science and Engineering, Jilin University \\ Changchun City, Jilin Province, China \\ ${ }^{2}$ College of Engineering Technology, Jilin Agricultural University \\ Changchun City, Jilin Province, China \\ 1dushuang234@sina.com, ${ }^{2} z$ uocc@jlu.edu.cn
}

\begin{abstract}
The pure electric vehicle with dual-energy storage system is driven under complex driving states. Owing to its nonlinear model, the fuzzy control is usually used in energy distribution. It is difficult for the conventional fuzzy controller without integral part to eliminate the static errors. Its control effect is not satisfactory. The required power minus actual power is the deviation. The self-adaptive fuzzy PI control adjusts the deviation values through tuning the parameters of PI controller in real time. Its control effect is satisfactory. The results of simulation experiment indicate that the self-adaptive fuzzy PI control is more economical than the fuzzy control under the same driving states.
\end{abstract}

Keywords: pure electric vehicle with dual-energy storage system, driving states, selfadaptive fuzzy PI control, energy distribution

\section{Introduction}

Nowadays, international environment is in the shortage of energy and serious pollution. Vehicle industry brings about convenience and comfortableness for us but it also consumes a lot of nonrenewable resources such as oil. Hybrid vehicles are a electric vehicle which have the most potential future in new energy vehicles since they have the advantages of energy conservation and environmental protection [1]. Electric vehicles need energy storage device when they are driven in normal mode. Chen Qingquan is the chairman of the International Electric Vehicle Association. He proposes that the ultra-capacitor can provide energy for electric vehicles which can make them start, accelerate and climb. Moreover, it also can retrieve regenerated energy which is caused during the electric vehicles braking. It has a broad prospect of application as auxiliary power of electric vehicles [2]. Energy storage device of pure electric vehicle with dual-energy storage is composed of batteries and ultra-capacitors. They cooperate with each other and drive the motor. The key issues of energy control are how distributes the energy of batteries and ultra-capacitors and coordinates the output better. The current methods of energy distribution are fuzzy control. Shi Qingshen of Shandong University suggests that fuzzy control can distribute the power factor of batteries. Batteries charge and discharge with large current can be decreased. The ultra-capacitor can charge and discharge with large current so the energy can be

${ }^{*}$ Chuncheng Zuo: Corresponding author 
retrieved during electric vehicles braking. It can enhance the power efficiency greatly [3]. However, the controller is equivalent to a PD controller near the origin when the system applies the fuzzy control. There are static errors in the control system and therefore the dynamic control effect is not ideal [4-5]. Bai Zhonghao of Hunan University proposes that fuzzy PI control can distribute energy of hybrid electric vehicles. The engine can work in the best area when fuzzy control distributes power factor of motor and the rules of fuzzy control change the parameter of PI in real time. It ensures the best fuel capability of vehicles [6]. But the available data rarely involve the fuzzy PI control in energy distribution of pure electric vehicle with dual-energy storage system. Fuzzy PI control is introduced into energy distribution system of pure electric vehicle with dual-energy storage system in the paper. It can eliminate the static errors of fuzzy control system effectively. The results of simulation experiment show that energy consumption and driving distance are improved through self-adaptive fuzzy PI control.

\section{The Structure and Power Distribution Principle of Pure Electric Vehicle with Dual-energy Control System}

\subsection{The structure of energy control system}

The energy control system of pure electric vehicle with dual-energy is comprised of dual-energy storage system, motor and controller, in which dual-energy storage system is the core of ensuring electric vehicles running well. Driving force of electric vehicles derives from the motor. The motor can also be used as the generator when the electric vehicles retrieve energy in braking [7]. The controller can make the electric vehicles start, accelerate, climb and brake when it controls batteries and the ultra-capacitor charge and discharge reasonably. So it can increase the life span and power performance of pure electric vehicles [8].



Figure 1. Structure diagram of energy control

\subsection{The principle of power distribution}

The working modes of dual-energy control system consist of batteries, ultracapacitors, braking and composite power which is composed of the first two. The power distribution principles decide what kind of mode the motor works [9].

Batteries and the ultra-capacitor need provide energy with the motor when it is used as electric motor. The motor need large power when the speed and torque of the vehicle are low. If batteries SOC (state of charge) is big and ultra-capacitor SOC is small, batteries power the motor separately. Both the ultra-capacitor and batteries power the motor in other cases. When the speed and torque of the vehicle stride over $P_{\mathrm{U}}$ line, they are moderate. The required power is small. If batteries SOC is small and ultra-capacitor SOC is big, the ultra-capacitor powers the motor separately. Batteries power the motor in other cases. When the speed and torque of 
the vehicle stride over $P_{\mathrm{C}}$ line, they are bigger than the former. The power distribution principle is the same as the first case.

When the motor is used as the generator, it charges batteries and the ultra-capacitor. The system is in the braking mode. The case lies below zero point of the horizontal axis in Figure 2. In order to ensure the ultra-capacitor charging and discharging appropriately, the regenerative braking energy is provided with it at first. When ultra-capacitor SOC is small, it absorbs all the braking energy. When ultra-capacitor SOC is big and batteries are small, batteries absorb the braking energy at first [10-13].

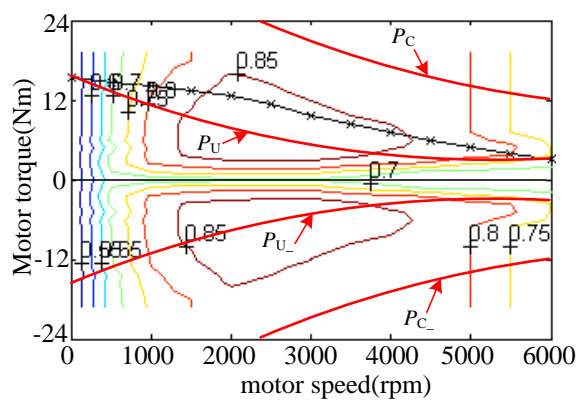

Figure 2. Diagram of motor efficiency and power distribution principle

\section{The Design of Self-adaptive Fuzzy PI Controller}

\subsection{The design of fuzzy controller}

Fuzzy controller summarizes its control rules through a large number of experimental data. The rules which are also expressed by fuzzy language based on operating experience. The largest difference between fuzzy control and traditional control is that fuzzy control does not need to know the mathematical model of the controlled object. The control can be done when we know the operating experience and data of the controlled object. Fuzzy controller is composed of four parts. They include fuzzification, fuzzy reasoning, fuzzy rule base and defuzzification. Its principle is that input exact value is become fuzzy quantity through fuzzification at first. Secondly, the fuzzy quantity is reasoned according to the fuzzy rules. Finally, the defuzzification model clears fuzzy quantity which is obtained through fuzzy reasoning [14-15]. The schematic diagram of fuzzy controller is shown in Figure 3.



Figure 3. Schematic diagram of fuzzy control

The number of input $x$ in the fuzzy controller is called the dimension of the fuzzy controller. We usually use the deviation $e$ as the input of fuzzy controller. Common structure of fuzzy controller is shown in Figure 4. Figure 4(a) is one-dimensional fuzzy controller. It adjusts the output signal $u$ by the change of deviation $e$. Its dynamic 
performance of control system is worse. Figure 4(b) is two-dimensional fuzzy controller. It adjusts the output signal by the deviation $e$ and the change rate of deviation $\dot{e}=\mathrm{de} / \mathrm{dt}$. Its dynamic performance of control system is better. Figure 4(c) is three-dimensional fuzzy controller. It adjusts the output signal by the variations of three components, namely, the deviation $e$, the change rate of deviation $\dot{e}$ and the change rate of the change rate of deviation $\ddot{e}=\mathrm{d}^{2} e / \mathrm{d} t^{2}$. Its dynamic performance of control system is fine in theory, but the increased dimensions of the input will lead to the increase of fuzzy reasoning computation. Generally, we don't select it as the structure of fuzzy controller [16]. The two-dimensional fuzzy controller is selected as the structure of fuzzy controller in the paper. The inputs of the controller are the power deviation $e$ and the change rate of deviation $\Delta e$.

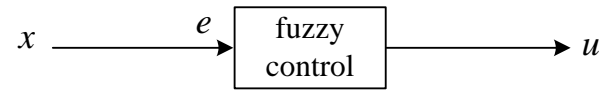

(a)

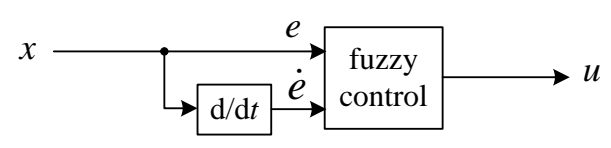

(b)

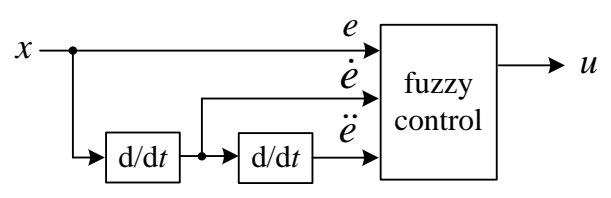

(c)

\section{Figure 4. Structure diagram of fuzzy controller}

After determining the structure of fuzzy controller, we start to quantize and fuzzify the input of fuzzy controller. The results of quantization and fuzzification can apply to fuzzy rules. In general, similar things can be classified several different levels such as big (B), middle (M) and small (S), or positive big (PB), positive middle (PM), positive small (PS), zero (O), negative small (NS), negative middle (NM) and negative big (NB). The more language description is, the more careful description of things is. But it is difficult to lay down control rules. Normally, there are two to ten fuzzy subsets in fuzzy domains. The fuzzy subsets of the input power deviation $e$ and change rate of deviation $\Delta e$ are $\{\mathrm{NB}, \mathrm{NM}, \mathrm{NS}, \mathrm{ZO}, \mathrm{PS}, \mathrm{PM}, \mathrm{PB}\}$ and their fuzzy domains are $\{-3,-2$, $-1,0,1,2,3\}$ in the system. The outputs of the fuzzy control are proportional coefficient $K_{\mathrm{p}}$ and integral coefficient $K_{\mathrm{i}}$. Their fuzzy subsets are\{S (small), SM (middle small), M (middle), LM (middle large ), L (large) $\}$ and their fuzzy domains are $\{0,0.25,0.5,0.75,1\}$.

Membership function is the characteristic function of fuzzy set. It includes triangular membership function (trimf), trapezoidal membership function (trapmf), $\mathrm{Z}$ membership function (zmf), S membership function (smf), Gauss membership function (gaussmf) and bell type membership function (gbellmf), etc. The paper adopts triangular membership function as the membership functions of inputs and outputs owing to its simple calculation and fast response. Their graphs are shown in Figure 5 and Figure 6. 
Select the interface of membership function in fuzzy control box of matlab and then select triangular membership function. Finally, input fuzzy subsets of the variables.

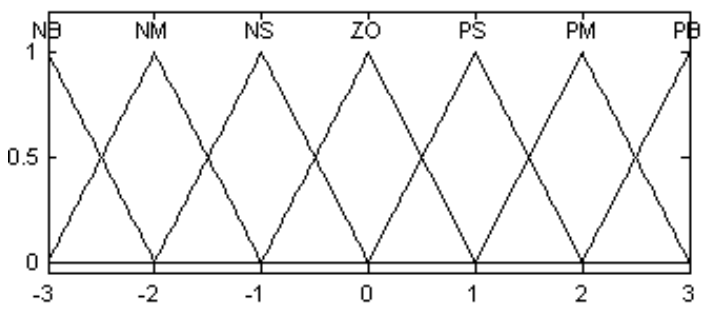

Figure 5. The membership function of $e$ and $\Delta e$



Figure 6. The membership function of $K_{\mathrm{p}}$ and $K_{\mathrm{i}}$

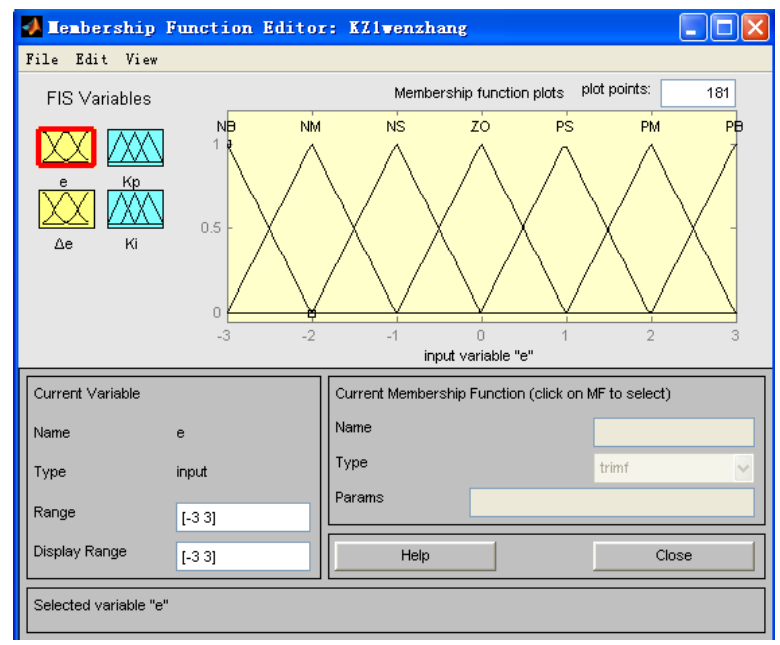

Figure 7. The interface of membership function in matlab

Fuzzy reasoning is the core of fuzzy controller. It is composed of a series of conditional statements of fuzzy rules. The fuzzy control system consists of two inputs and two outputs in the paper. The statement expression of control rule is:

$$
\text { If } \mathrm{A} \text { and } \mathrm{B} \text {, then } \mathrm{C} \text { and } \mathrm{D}
$$

According to the above description, the simulink model of fuzzy control is shown in Figure 8 , in which the edited interface of overall fuzzy control system is shown in Figure 9. 




Figure 8. The model of fuzzy control

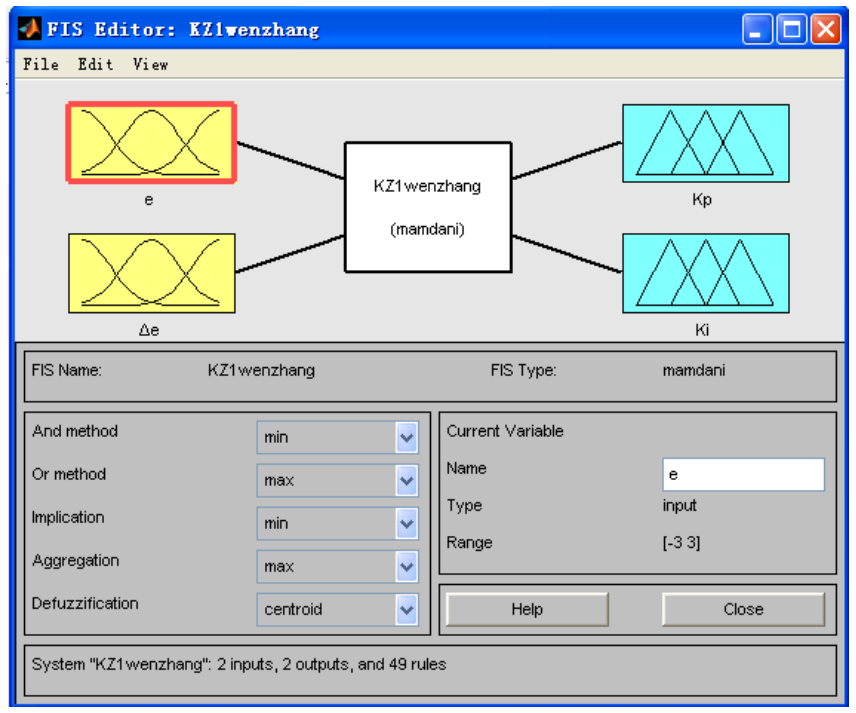

Figure 9. The edited interface of fuzzy control

\subsection{The design of PI controller}

The algorithm of PI control is simple and its robustness is strong. It is widely used in automatic control system. It calculates the control quantity by means of the different combination of proportional errors and integral errors. The common PI algorithm is:

$$
u(t)=K_{\mathrm{p}}\left[e(t)+\frac{1}{T_{1}} \int_{0}^{t} e(t) d t\right]
$$

Where: $e(t)=r(t)-y(t)$ : the deviation signal between given value $r(t)$ and measured value $y(t) ; K_{\mathrm{p}}$ : proportional coefficient; $T_{1}$ : integral time constant; $K_{\mathrm{i}}$ : integral coefficient, and $K_{\mathrm{p}}$ divided by $T_{1}$ equals $K_{\mathrm{i}} . K_{\mathrm{p}}$ can both amplify error signal and accelerate the response speed of the system. But $K_{\mathrm{p}}$ is too large, the system will cause the static error of output. Integral coefficient $K_{\mathrm{i}}$ is proportional to the integral of the error signal. If the system has the static error, the integral will increase with time. The error will be accumulated in the integral state constantly until the static error is eliminated. But $K_{\mathrm{i}}$ is too large, the system will slow down the modulation speed of the system and lead to the oscillation of the system [17-19].

The dynamic response curve is shown in Figure 10. The curve can be divided into five parts, i.e., $\mathrm{OA}, \mathrm{AB}, \mathrm{BC}, \mathrm{CD}$ and $\mathrm{DE}$. In section $\mathrm{OA}, y$ is less than $r$, so the deviation is less than zero. The change rate of the deviation is more than zero since the slope of $\mathrm{OA}$ is more than zero. In section AB, $y$ is more than $r$, so the deviation is more than zero. The change rate of the deviation is also more than zero. In section BC, $y$ is more than $r$, so the deviation is 
more than zero. The change rate of the deviation is less than zero since the slope of BC is less than zero. In section CD, $y$ is less than $r$, so the deviation is less than zero. The change rate of the deviation is also less than zero. In section DE, $y$ is less than $r$, so the deviation is less than zero. The change rate of the deviation is more than zero. The established fuzzy rules should speed up the response of system and reduce the overshoot as far as possible. For example, the output value of fuzzy controller should be greater in order to accelerate the response speed of the system in section OA. Near A point, the output value should be reduced immediately in order to avoid overshooting [20-22]. According to the above principles, we establish the fuzzy rule of PI control:

1. When $e$ is less than zero and $\Delta e$ is more than zero, $K_{\mathrm{p}}$ changes first big and small and $K_{\mathrm{i}}$ changes first small and big.

2. When $e$ is more than zero and $\Delta e$ is more than zero, $K_{\mathrm{p}}$ changes first small and big and $K_{\mathrm{i}}$ changes first big and small.

3. When $e$ is more than zero and $\Delta e$ is less than zero, $K_{\mathrm{p}}$ changes first big and small and $K_{\mathrm{i}}$ changes first small and big.

4. When $e$ is less than zero and $\Delta e$ is less than zero, $K_{\mathrm{p}}$ changes first small and big and $K_{\mathrm{i}}$ changes first big and small.

5. When $e$ is less than zero and $\Delta e$ is more than zero, $K_{\mathrm{p}}$ changes first big and small and then stabilizes gradually. $K_{\mathrm{i}}$ changes first small and big and then stabilizes gradually.

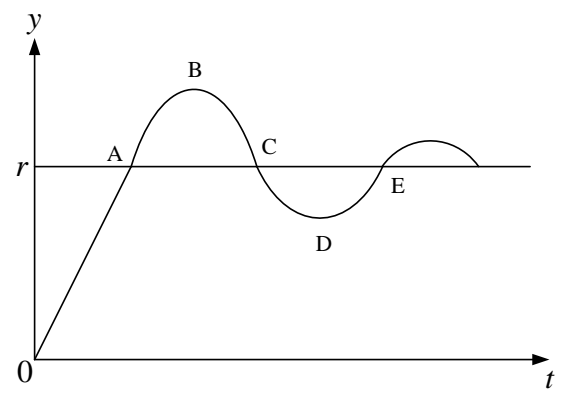

\section{Figure 10. The dynamic response curve}

Lay down fuzzy rule sets for control center according to the above fuzzy control rules. Control statement is (1). The fuzzy control rules of $K_{\mathrm{p}}$ and $K_{\mathrm{i}}$ are in Table 1 and Table 2.

Table 1. Fuzzy control rule of $K_{\mathrm{p}}$

\begin{tabular}{|c|c|c|c|c|c|c|c|}
\hline \multirow{2}{*}{$\Delta$} & \multicolumn{7}{|c|}{$e$} \\
\cline { 2 - 8 } & NB & NM & NS & ZO & PS & PM & PB \\
\hline NB & L & LM & M & LM & M & LM & LM \\
\hline NM & LM & M & SM & M & SM & SM & LM \\
\hline NS & LM & SM & SM & SM & S & SM & M \\
\hline ZO & M & S & S & S & S & S & M \\
\hline PS & LM & SM & S & SM & S & S & SM \\
\hline PM & LM & M & SM & M & S & SM & SM \\
\hline PB & L & LM & M & L & SM & SM & SM \\
\hline
\end{tabular}


Table 2. Fuzzy control rule of $\boldsymbol{K}_{\mathrm{i}}$

\begin{tabular}{|c|c|c|c|c|c|c|c|}
\hline \multirow{2}{*}{$\Delta e$} & \multicolumn{7}{|c|}{$e$} \\
\cline { 2 - 8 } & NB & NM & NS & ZO & PS & PM & PB \\
\hline NB & S & LM & L & S & M & S & S \\
\hline NM & LM & L & M & S & SM & M & S \\
\hline NS & L & M & SM & S & SM & SM & M \\
\hline ZO & L & LM & SM & SM & SM & M & L \\
\hline PS & LM & SM & SM & S & S & SM & SM \\
\hline PM & M & LM & SM & S & S & S & S \\
\hline PB & S & SM & LM & S & S & S & S \\
\hline
\end{tabular}

The forty-nine fuzzy control rules include all situations that the working process of the control system could encounter. Use the fuzzy box, input control rules and then fuzzy rule base will be obtained. Parts of the fuzzy rule sets are shown in Figure 11.

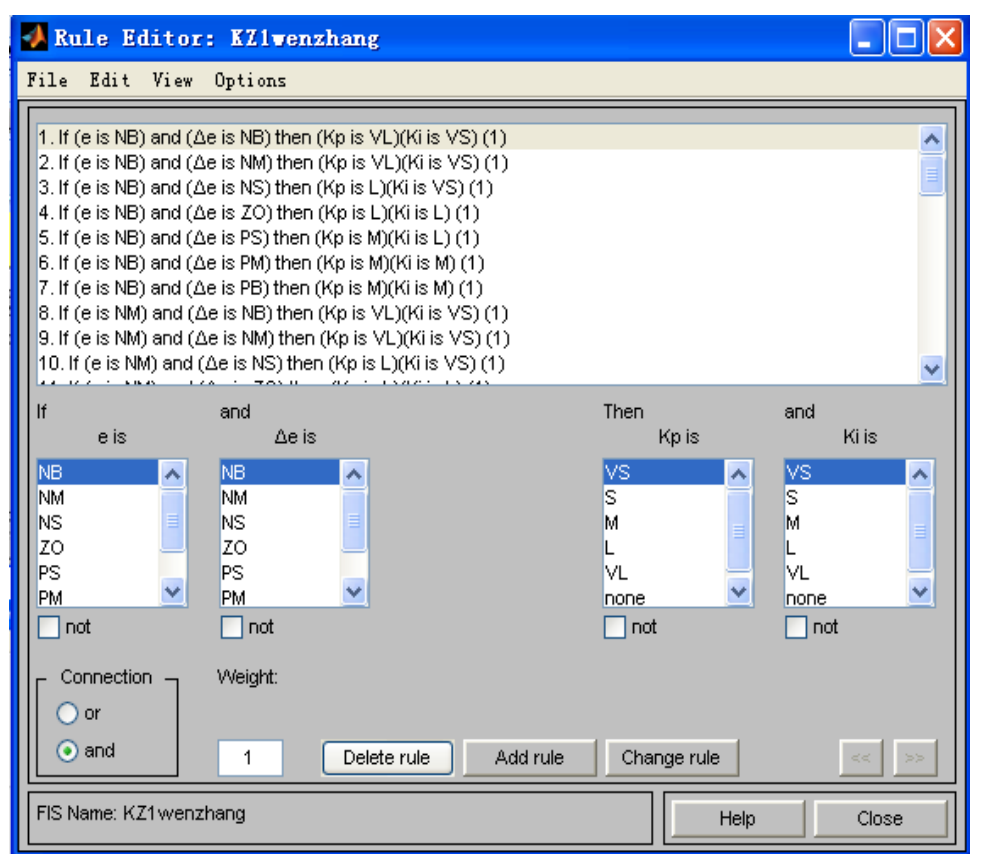

Figure 11. Parts of the fuzzy rule sets

After we finish designing the fuzzy controller of the system, we can obtain the change surface of proportional coefficient $K_{\mathrm{p}}$ and integral coefficient $K_{\mathrm{i}}$ with the deviation $e$ and the change rate of the deviation $\Delta e$.

The model of PI control alone is shown in Figure 14. 


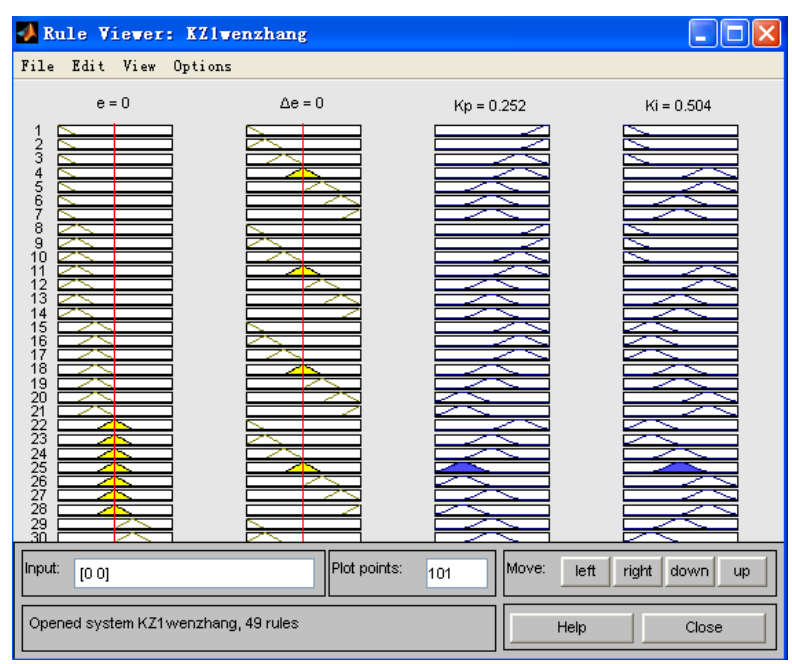

Figure 12. The fuzzy control rule base

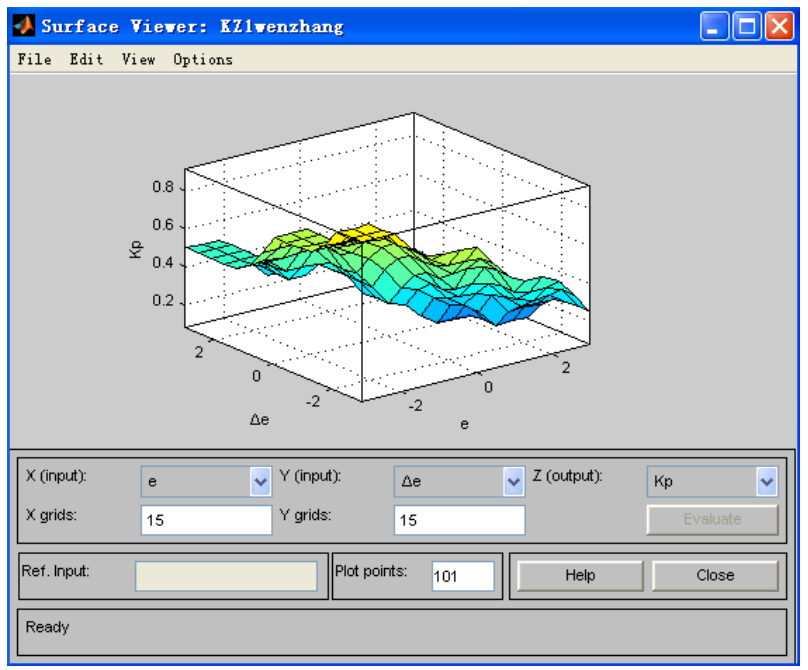

Figure 13. The change surface of $K_{\mathrm{p}}$ and $K_{\mathrm{i}}$ with $e$ and $\Delta e$



Figure 14. The model of PI control 


\subsection{The principle of self-adaptive fuzzy PI control}

In many cases, electric vehicles are driven in complex situations. The speed of the vehicles need be adjusted frequently. Energy distribution of pure electric vehicle with dual-energy storage system need be controlled in real time and requirements for the control precision are higher. Self-adaptive fuzzy PI control is composed of fuzzy controller and PI controller. The schematic diagram is shown in Figure 15.

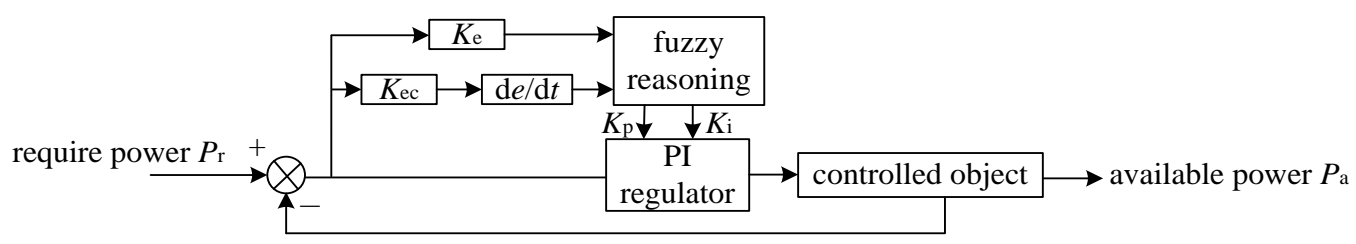

Figure 15. The schematic diagram of self-adaptive fuzzy PI

The system compares given power with actual power and then it will obtain the deviation $e$. According to the fuzzy relationship between proportional coefficient $K_{\mathrm{p}}$ and integral coefficient $K_{\mathrm{i}}$ of PI control and the system deviation $e$ and the change rate of deviation $\Delta e$, the system adopts the fuzzy reasoning and modifies $K_{\mathrm{p}}$ and $K_{\mathrm{i}}$ online. It can satisfy the different driving states demand of electric vehicles. The adjustment steps are as follows. Above all, according to the given power and the actual power, the system calculates the deviation $e$ and the change rate of deviation $\Delta e$. The outputs of the system are $K_{\mathrm{p}}$ and $K_{\mathrm{i}}$. Secondly, process the fuzzy domains of input variables and output variables by means of quantification factor. And the fuzzy controller can adjusts quantification factor according to the practical requirement. At last, the fuzzy reasoning is done on the basis of the fuzzy rules. So the parameters of PI controller can be controlled in real time and the system can complete the adjustment of controlled object. The algorithm is widely used in nonlinear system since it can adjust the parameters automatically [23-24].

\subsection{The model of self-adaptive fuzzy PI control}

The simulink model of self-adaptive fuzzy PI control of pure electric vehicle with dualenergy in matlab is shown in Figure 16. The first fuzzy controller is used to allocate the power of batteries and the ultra-capacitor. The self-adaptive fuzzy PI controller consists of the second fuzzy controller and PI controller. The inputs of fuzzy controller are required power and actual power. The inputs of PI controller are the output of fuzzy controller and the deviation of power.

\section{Simulation Experiments and Results Analysis of Self-adaptive Fuzzy PI Control}

The driving state of the system adopts city six cycle cases. The speed curve of input is shown in Figure 17. The total vehicle weight of pure electric vehicle with dual-energy is $520 \mathrm{~kg}$, maximum speed is $50 \mathrm{~km} / \mathrm{h}$, frontal area is $10.5 \mathrm{~m}^{2}$, maximum gradeability is $15 \%$, rolling radium is $30 \mathrm{~cm}$, coefficient of aero dynamic drag is 0.35 and coefficient of rolling resistance is 0.015 . The battery is lead-acid battery. The rated voltage of single battery is $6 \mathrm{~V}$ and the rated capacity is $180 \mathrm{~A} \cdot \mathrm{h}$. The system uses six battery modules. The rated voltage of ultra-capacitor is $48 \mathrm{~V}$ and the rated capacity is $165 \mathrm{~F}$. The rated power of the motor is $3 \mathrm{kw}$ and maximum speed is $6000 \mathrm{rpm}$. Its rated voltage is $36 \mathrm{~V}$. Compare the fuzzy control with 
self-adaptive fuzzy PI control in matlab/simulink, the results of the simulation experiment are shown in Figures 18-23.

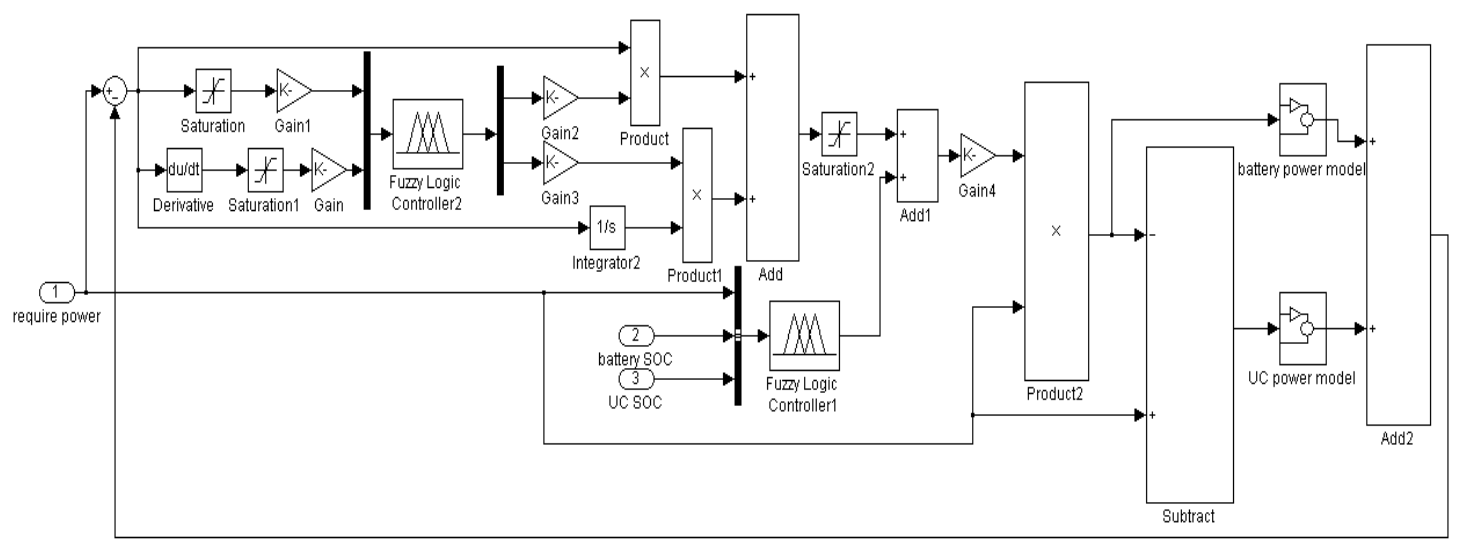

Figure 16. The simulation model of self-adaptive fuzzy PI control

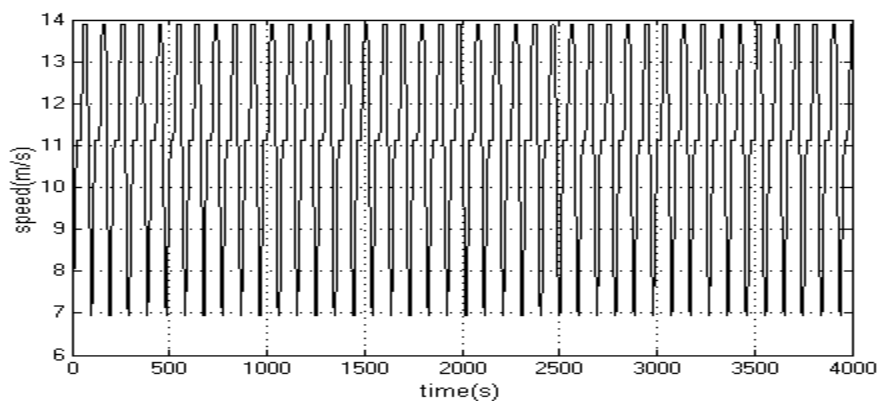

Figure 17. The city six cycle cases

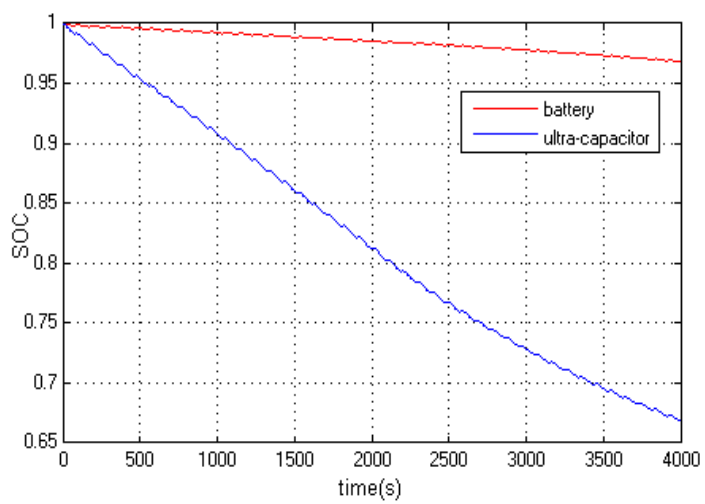

Figure 18. The SOC curve of battery and ultra-capacitor in fuzzy control 




Figure 19. The SOC curve of battery and ultra-capacitor in self-adaptive fuzzy PI control

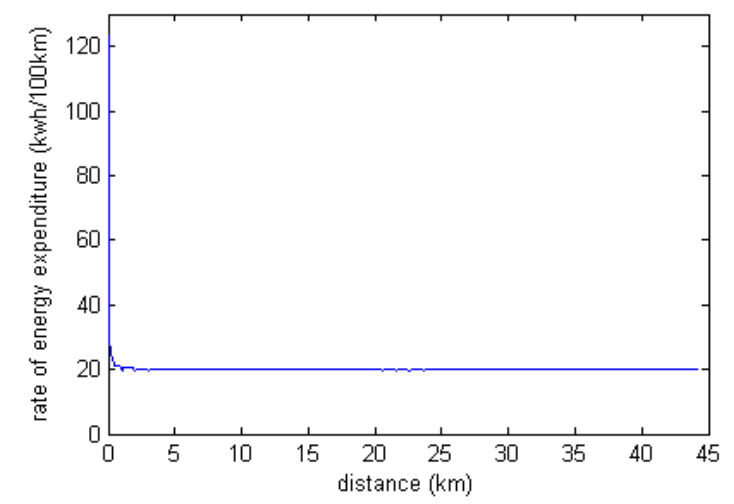

Figure 20. The curve between energy consumption and distance in fuzzy control

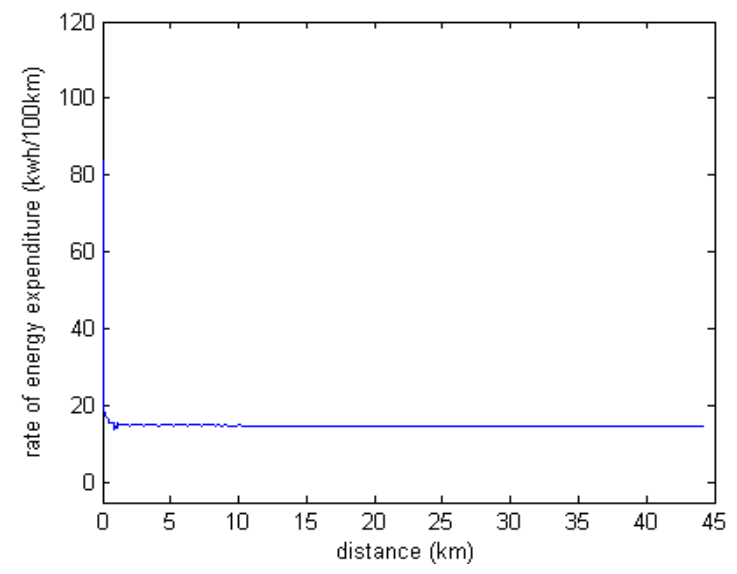

Figure 21. The curve between energy consumption and distance in selfadaptive fuzzy PI control 


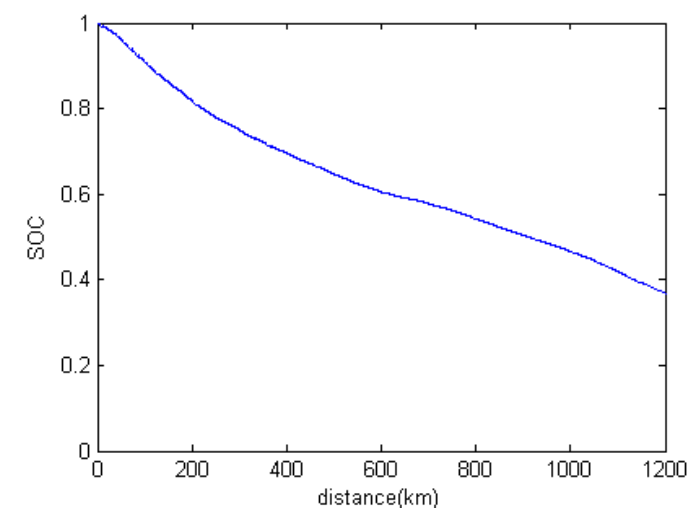

Figure 22. The curve between distance and SOC in fuzzy control

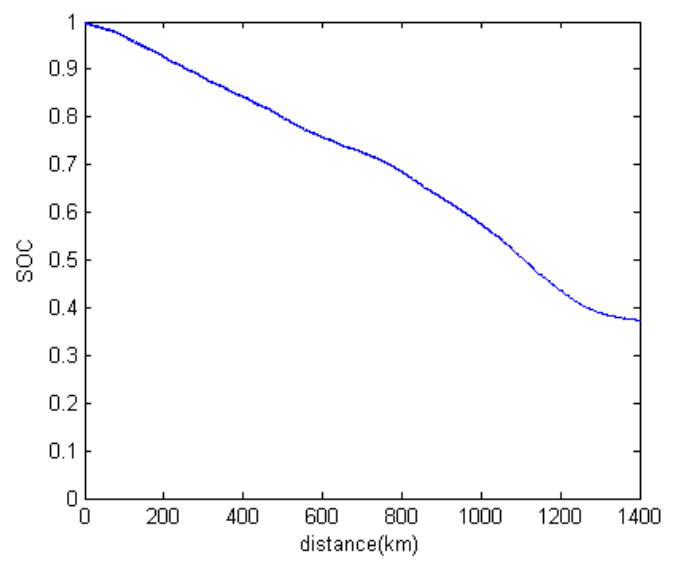

Figure 23. The curve between distance and SOC in self-adaptive fuzzy PI control

From Figure 18 and Figure 19, we can draw the conclusion that SOC of batteries and the ultra-capacitor decreases conformably in two kinds of control algorithms. In the fuzzy control algorithm, SOC of batteries is decreased to 0.97 and SOC of the ultra-capacitor is decreased to 0.67. In self-adaptive fuzzy PI control algorithm, SOC of batteries is decreased to 0.985 and SOC of the ultra-capacitor is decreased to 0.816. The SOC decline of batteries and the ultra-capacitor is less in self-adaptive fuzzy PI control algorithm than in fuzzy control algorithm. SOC curve of the ultra-capacitor is smooth since self-adaptive fuzzy PI control can eliminate the static errors and resist interferences strongly. So its control efficiency is higher than fuzzy control. From Figure 20 and Figure 21, we can draw the conclusion that the energy consumption rate of the electric vehicle in a hundred kilometer is $20 \mathrm{kwh} / 100 \mathrm{~km}$ in fuzzy control algorithm. The energy consumption rate of the electric vehicle in a hundred kilometer is $17 \mathrm{kwh} / 100 \mathrm{~km}$ in self-adaptive fuzzy PI control algorithm. The latter is $15 \%$ lower than the former. It indicates self-adaptive fuzzy PI control can enhance economy of electric vehicles. From Figure 22 and Figure 23, when SOC of batteries is down to about 0.38, the mileage of the electric vehicle is $1200 \mathrm{~km}$ in fuzzy control algorithm. When SOC of batteries is down to about 0.38 , the mileage of the electric vehicle is $1400 \mathrm{~km}$ in self-adaptive fuzzy PI control algorithm. The latter is more 200 kilometers than the former. It explains self-adaptive fuzzy PI control can increase driving range of electric vehicles. 


\section{Conclusions}

Energy control system of pure electric vehicle adopts self-adaptive fuzzy PI control as the control algorithm in the paper. The control system is verified by simulink simulation. The results of simulation experiment indicate that the system has good control effect, can eliminate the static errors in the process of control and resist interferences strongly. Compared the self-adaptive fuzzy PI control with the fuzzy control, there is greater improvement in control accuracy and stability. Through the comparison between self-adaptive fuzzy PI control and traditional fuzzy control, we analyze and draw the conclusion that adaptive fuzzy PI control can reduce the energy consumption of electric vehicle and prolong the mileage of the electric vehicle. It can also improve the life span of the batteries.

\section{Acknowledgements}

The authors are grateful to the Project of Scientific and Technical Development Plan of Jilin Province of China ( No. 20080353) and the Young Start-up Funding Project of Jilin Agricultural University of Jilin Province of China (N0. 201233).

\section{References}

[1] Y. Yuanbin, W. Qingnian, W. Weihua and Z. xiaohua, "Parameter matching of mild hybrid electric vehicle with compound power supply", Journal of Jilin University (Engineering and Technology Edition), vol. 2, no. 39, (2009).

[2] A. M. Namisnyk, "A Survey of Electrochemical Supercapacitor Technology", A Dissertation Submitted for the Degree of Bachelor, (2003) Faculty of Engineering in University of Technology, Sydney.

[3] S. Qingsheng, Z. Chenghui and C. Naxin, "Optimal Control of Energy Management in Novel Electric Vehicles With Dual-Source Energy Storage System”, Transactions of China Electrotechnical Society, vol. 23, no. 8, (2008).

[4] Z. Zhenwei and F. Zhihua, "Design and simulation of fuzzy control system based on MATLAB", Journal of Suzhou University (Engineering and Technology Edition), vol. 2, no. 24, (2004).

[5] Z. Dao and Q. Xiaohui, "Comparison of simulation between fuzzy-PI dual-mode controller and fuzzy controller", Journal of Science Technology and Engineering, vol. 11, no. 9, (2009).

[6] B. Zhonghao, W. Yaonan and C. Libo, "Research on Adaptive Fuzzy Control of the Energy of Hybrid Electric Vehicle", Automotive Engineering, vol. 27, no. 4, (2005).

[7] Z. Changli, Z. Yajun, Y. Maode and W. guiping, "Fuzzy control modeling and simulation of regenerative braking system for pure electric vehicle with dual-source energy storage system", Journal of System Simulation, vol. 2, no. 23, (2011).

[8] B. -H. Lee, D.-H. Shin, H. S. Song, H. Heo and H. J. Kin, "Development of an advanced hybrid energy storage system for hybrid electric vehicles", Journal of Power Electronics, vol. 1, no. 9, (2009).

[9] A. W. Stienecker, T. Stuart and C. Ashtiani, "A Combined Ultracapacitor-Lead Acid Battery Energy Storage System for Mild Hybrid Electric Vehicles”, SAE Paper, (2005), pp. 350-355.

[10] Z. Kaiwen, "Research on key Technologies of the Composite Power Based on the Electric Vehicles", A Dissertation Submitted for the Degree of Master, (2012), Wuhan University.

[11] L. Qiaohua, "Composite Power of the Electric Vehicle Simulation of Control", A Dissertation Submitted for the Degree of Master, (2012), Changsha University of Science and technology.

[12] W. Conghui, "Fuzzy Logic Control Strategy of Energy Management System for Hybrid Electric Vehicles", A Dissertation Submitted for the Degree of Master, (2011), Henan University of science and Technology.

[13] L. Jingjing, "Investigation and Simulation of Combined Energy Storage System of Fuel Cell and Ultracapacitor", A Dissertation Submitted for the Degree of Master, (2006), Wuhan University of Technology.

[14] H. weihua and F. Kangling, "System and Application of Fuzzy Control", Publishing House of Electronics Industry, Beijing, (2012).

[15] Z. Guoyong, S. Yong and W. Youlin, "Fuzzy PID Position Control Approach in Computer Numerical Control Machine Tool", Journal of Computers, vol. 8, no. 3, (2013).

[16] T. Binyong, L. Linji and W. Wenjie, "Fuzzy Control Theory and Application Technology", Tsinghua University Press, Beijing, (2012).

[17] W. Zhenlin and G. Yangkuan, "System simulation of MATLAB/Simulink and process control”, Publishing House of Electronics Industry, Beijing, (2012). 
[18] Z. Qian, "Research on Fuzzy PI Control of Two-Phase Hybrid Stepping Motor", A Dissertation Submitted for the Degree of Master, (2010), Zhejiang University.

[19] C. Ping and W. Yongchu, "Research of Fuzzy PI Controller Based on Error Integral", Journal of Fujian University of Technology, vol. 6, no. 4, (2006).

[20] G. Fengjian, "Research and Design of Brushless DC Motor Control System for Electric Vehicle", A Dissertation Submitted for the Degree of Master, (2011), Shandong University of Technology.

[21] A. M. Davem and C. Guanrong, "Design and analysis of a fuzzy proportional-integral-derivative controller", Elsevier Science on Fuzzy Sets and Systems, vol. 79, (1996).

[22] C. Bo, "Research and realization of Speed Regulation of no Brush dc Motor Based on Fuzzy PID Algorithm", A Dissertation Submitted for the Degree of Master, (2012), University of Electronic Science and technology.

[23] L. Wang and W. Bai, "Development and simulation of electric vehicle based on ADVISOR", Journal of southeast University (English Edition), vol. 2, no. 22, (2006).

[24] C. B. Andrew and E. Ali, "ADVISOR-based model of a battery and an ultra-capacitor energy source for hybrid electric vehicles”, IEEE Transactions on Vehicular Technology, vol. 1, no. 53, (2004).

\section{Authors}



Shuang Du. She was born in Changchun, China in 1977. Now, she is a Ph.D. student in College of Mechanical Science and Engineering of Jilin University. Her major field of study is mechanical design and theory. She has been worked in Jilin Agricultural University since 2006. She is a lecturer of College of Engineering Technology in Jilin Agricultural University. Her current research interest is automatic control of electric vehicles.



Chuncheng Zuo was born in Fanshi County, China in 1963. He received his doctor degree in biological and agricultural engineering, Jilin University, Changchun, China, 1991. His major field of study is agricultural machinery. He has been worked in Jilin University since 1991. He is a doctoral supervisor and a professor of Jilin University. He has published more than a hundred papers, in which seventy-eight were indexed by SCI, EI and ISTP. His current research interests are microfluidic batteries and new energy vehicles. 
International Journal of Control and Automation Vol.7, No.3 (2014) 